\title{
Interactive comment on "Will climate change increase the risk of infrastructure failures in Europe due to heavy precipitation?" by Katrin M. Nissen and Uwe Ulbrich
}

\section{Anonymous Referee \#1}

Received and published: 28 November 2016

1) General comments. The paper entitled "Will climate change increase the risk of infrastructure failures in Europe due to heavy precipitation?" investigates a novel technique in the identification of heavy precipitation events, besides the frequency, other parameters (such as: event size, duration and severity) being analyzed. It is well known the direct relationship between these parameters which characterize many others natural hazards and the increasing the values of the associated risks. The paper is focused on data sets analysed, the methods used (taken from the engineering literature -3 . Thresholds) for the determination of the thresholds of relevant events, and the identification of climate change signals, as the authors state (page 2, rows 18-21). Starting from this point, some critical issues of the paper must be solved. A

Printer-friendly version

Discussion paper 
first major drawback is related to the discrepancy between the title of the paper and its content. Aside from some references taken from the literature that aim to determine the thresholds that must be considered by the infrastructure designers and providers (3. Thresholds), there are no others approaches on the general concept named and widespread used: element of risk (as part of the risk assessment). For a detailed framing of the content of this paper in the scientific approaches of the risks associated with natural hazards, you can consult many papers (e.g. van Westen, 2013). A second major conceptual approach that must be reframed refers to much more complexity of the impact of meteorological events on the infrastructural lifelines. There are some examples (pag. 1, rows 12-17) but this part of the paper, I think, should be improved. Also the spatio-temporal relations between different natural hazards (e.g. precipitations that trigger floods and/or landslides etc.) must be detailed. You can see the paper of Gill and Malamud, 2014. Others references between climate changes and predicted associated hazards you can find in Gariano and Guzzetti, 2016. Using these few references (and why not the others) the authors could substantially increase the conceptual part of the paper, both in the Introduction part but even in the first paragraph (this must be rephrased) of the 3rd part. For solving these problems, I can suggest 2 ways: (i) modify the title of the paper according to the main results of the paper (otherwise with novel results in the field), or (ii) try to emphasize (theoretically and more exemplified) the risk approach, by taking into account your results as a complete societal relevance.

2) Specific comments When we use the abbreviations we must to detail the meaning starting from the first use. For others specific comments, please download the attached file.

Bibliography: Gariano SL, Guzzetti F (2016) Landslides in a changing climate, Earth-Science Reviews, 162, 227-252. Gill JC, Malamud BD (2014) Reviewing and visualizing the interactions of natural hazards, Rev. Geophys., 52, 680-722. Van Westen, CJ (2013) Remote Sensing and GIS for Natural Hazards Assessment and Disaster Risk Management. In: Treatise on Geomorphology / ed. by John F. Schroder

Printer-friendly version Discussion paper 
and M.P. Bishop. San Diego, Academic Press, Elsevier, pp. 259-298.

NHESSD

Please also note the supplement to this comment:

http://www.nat-hazards-earth-syst-sci-discuss.net/nhess-2016-337/nhess-2016-337-

RC1-supplement.pdf

Interactive comment on Nat. Hazards Earth Syst. Sci. Discuss., doi:10.5194/nhess-2016-337, 2016.

Interactive

comment 